\title{
SUPERCONDUCTING INTERMEDIATE-VELOCITY DRIFT-TUBE CAVITIES FOR THE RIA DRIVER LINAC*
}

\author{
K. W. Shepard, M. Kedzie, and M. P. Kelly, ANL, Argonne, IL, 60540, USA \\ T. Schultheiss, Advanced Energy Systems, Inc. , Medford, NY, 11763, USA
}

\section{Abstract}

This paper reports the status of prototypes for two types of niobium superconducting drift-tube cavity. The structures are intended for use in the ion-linac driveraccelerator for the proposed rare-isotope accelerator (RIA) facility, and cover an intermediate range of particle velocities, $0.18<$ beta $<0.5$. Both structures fit within a cylindrical housing of roughly 18 inch diameter and 15 inch length, and incorporate two drift tubes to define the accelerating field. The cavity types are a $172.5 \mathrm{MHz}$ lollipop-loaded cavity for (peak) beta $=\mathrm{v} / \mathrm{c}=0.19$, and a $345 \mathrm{MHz}$ spoke-loaded cavity for beta $=0.4$. The results of numerical electromagnetic and mechanical simulations will be presented and several evolving design features discussed. These include, for example, a design for an integral stainless-steel helium jacket which provides for very good frequency stability against changes in helium pressure. We also discuss the reduction of beam steering effects using small, asymmetric changes in the drift-tube geometry.

\section{INTRODUCTION}

Recent development at ANL of SC niobium cavities has focused on accelerating structures suitable for the proposed rare isotope accelerator (RIA)[1,2]. In several earlier papers we have presented preliminary designs for a full set of drift-tube cavities suitable for the RIA driver linac $[3,4]$. Here we update and discuss in more detail the design of two cavities which cover the relatively unexplored range of intermediate velocities, $0.2<\beta=\mathrm{v} / \mathrm{c}<0.6$.
The two cavities, shown in section in Fig. 1, are a 172.5 $\mathrm{MHz}$ lollipop-loaded structure and a $345 \mathrm{MHz}$ spokeloaded structure.

We note that several single-cell SC spoke cavities have already been built and tested $[5,6,7]$. Many cavities will be required for the $1.3 \mathrm{GeV}$ RIA driver linac, so that multi-cell cavities will be much more efficient. For the accelerating structures discussed here, two cells have been settled on as providing the best balance between maximizing voltage gain and maximizing velocity acceptance [2].

It should also be noted that the cavities described here operate at multiples of $(805 / 14) \mathrm{MHz}$, reflecting a recent shift in the bunch frequency of the RIA driver to permit using in the final sections of the RIA driver linac the same $805 \mathrm{MHz}$ SC cavities and cryomodules being developed for the SNS project.

\section{CAVITY PROPERTIES}

\subsection{Electromagnetic Properties}

The electromagnetic properties of the cavities have been numerically modeled using the codes MAFIA and also CST Microwave Studio. Table 1 shows the principal parameters. An aluminum $86 \%$ scale model of the spoke cavity was built to check and correct frequency before cutting niobium. Perturbation measurements of the EM fields generally confirmed the numerical results to within a few percent.

Note that the OD of the housing of the lollipop cavity is
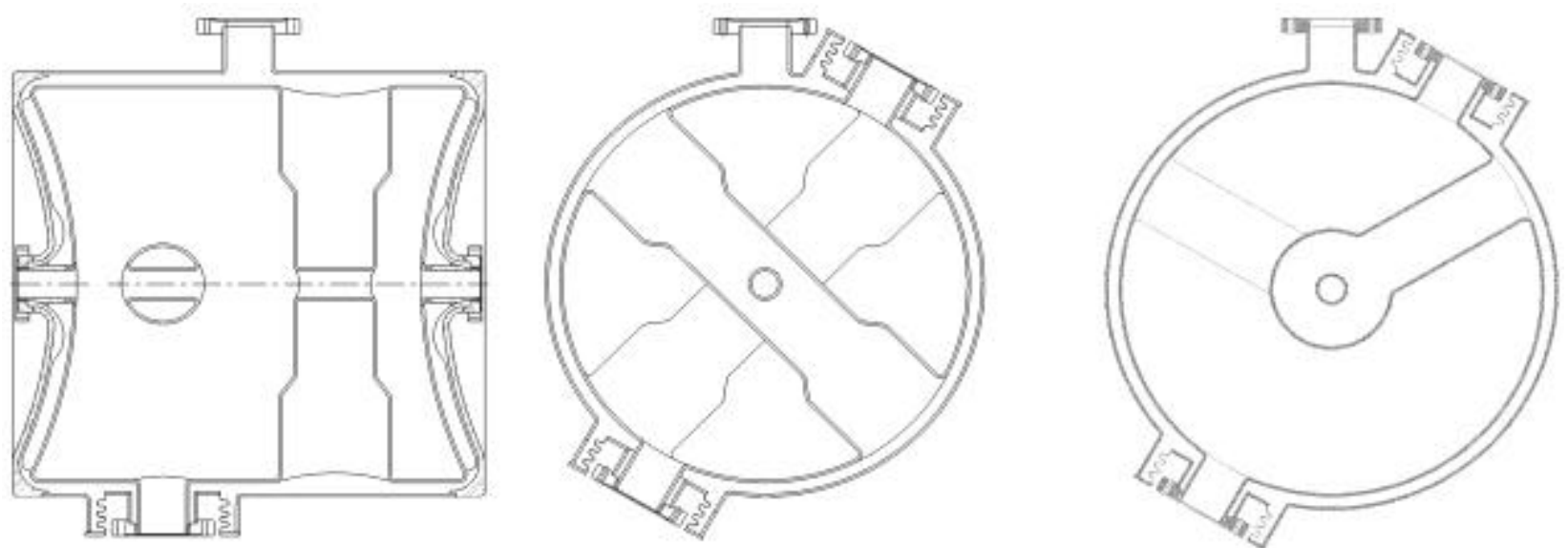

Figure 1: Side and end sectional view of the $345 \mathrm{MHz}$ two-cell spoke cavity, and end section of the $172.5 \mathrm{MHz}$ twocell lollipop cavity. The housing OD is $48.6 \mathrm{~cm}$ for the spoke cavity and $51.6 \mathrm{~cm}$ for the lollipop.

*Work supported by the U. S. Department of Energy under contract W-31-109-ENG-38. 
Table 1: Principal parameters of the cavities.

\begin{tabular}{|l|l|l|}
\hline \multicolumn{1}{|c|}{ Parameter } & \multicolumn{1}{c|}{ Lollipop } & \multicolumn{1}{c|}{ Spoke } \\
\hline Frequency & $172.5 \mathrm{MHz}$ & $345 \mathrm{MHz}$ \\
\hline Active Length & $36 \mathrm{~cm}$ & $38 \mathrm{~cm}$ \\
\hline Diameter & $47.8 \mathrm{~cm}$ & $44.8 \mathrm{~cm}$ \\
\hline Frequency & $172.5 \mathrm{MHz}$ & $345 \mathrm{MHz}$ \\
\hline Rf Energy* & $158 \mathrm{millijoule}$ & $152 \mathrm{millijoule}$ \\
\hline $\mathrm{E}_{\mathrm{pk}} *$ & $3.8 \mathrm{MV} / \mathrm{m}$ & $3.5 \mathrm{MV} / \mathrm{m}$ \\
\hline $\mathrm{B}_{\mathrm{pk}} *$ & $118 \mathrm{Gauss}$ & $86 \mathrm{Gauss}$ \\
\hline $\mathrm{QRs}$ & 49 & 85 \\
\hline $\begin{array}{l}\text { Voltage Gain at } \\
5 \mathrm{MV} / \mathrm{m}, 30 \text { phase }\end{array}$ & $1.56 \mathrm{MV}$ & $1.65 \mathrm{MV}$ \\
\hline
\end{tabular}

$*$ At an accelerating gradient of $1.0 \mathrm{MV} / \mathrm{m}$

$3 \mathrm{~cm}$ larger than for the spoke cavity. Initially, we had hoped to keep the diameter of the lollipop cavity the same as that of the spoke cavity, in order to benefit from using the same tooling for both structures. This constraint on diameter produced an unacceptably high peak magnetic field for the lollipop cavity, $\mathrm{B}_{\mathrm{pk}}=161$ gauss $/(\mathrm{MV} / \mathrm{m})$ [4]. In the present design, the diameter of the inductive stem was increased, which decreased $\mathrm{B}_{\mathrm{pk}}$ to 118 gauss, but required an increase in diameter of $3 \mathrm{~cm}$ to keep the frequency at $172.5 \mathrm{MHz}$. This diameter increase is sufficiently small, however, that a single cryostat design will still be adequate for both cavities.

\subsection{Mechanical Properties}

A primary mechanical requirement is that the cavities be sufficiently stiff that fluctuations of pressure in the helium cooling bath do not induce excessive RF frequency shift and phase noise.

In this regard, the end-faces of the cavity are particularly critical and have been dished-in, with a spherical radius of $51.3 \mathrm{~cm}$. They have also been reinforced with 12 radial gussets formed of 1/4 inch niobium welded to the exterior side of the niobium dished ends.

Another technique for reducing pressure-induced deformation is to join the cavity to an integral jacket to contain the liquid helium. By attaching the jacket to the cavity at the beam ports, the inward pressure on the niobium cavity ends can be balanced by the outward pressure on the helium jacket. With the cavity end face thus effectively supported at both the OD and the center beam port, the resultant strain on the niobium end face in effect forms a toroidal bulge with maximum inward dis placement at roughly half the cavity diameter.

Note that the electromagnetic fields on the interior surface of the end flange are predominately electric near the beam axis and predominately magnetic near the outer diameter. An inward deflection in a region of magnetic surface field raises the RF frequency and in a region of electric field lowers it. By properly shaping the support gussets, the profile of the inward bulge can be controlled in such a way as to balance the two terms, and substantially reduce the net frequency shift. The 345 $\mathrm{MHz}$ spoke cavity design shown in Figure 1 has been tailored in this manner using numerical FEL modeling of the mechanical properties. The estimated maximum deflection caused by application of 21 PSI helium pressure is .005 inch. The effect on RF eigenfrequency from this deformation on both end-faces is estimated to be $6 \mathrm{KHz}$. Such a result compares favorably with the observed shift of approximately $100 \mathrm{KHz}$ in the single cell prototype spoke cavity under similar circumstances [4].

The integral helium jacket is essentially the same in both the spoke and lollipop cavities and is formed of $1 / 8$ inch stainless-steel (SS) sheet for the cylindrical portion, and $1 / 4$ inch SS on the ends, with the corner reinforced by flanging as shown. At the beam ports the transition from niobium to SS will be made either by brazing, or by beam-welding with a vanadium transition section.

\section{INTERACTION WITH BEAM}

Figure 2 shows the voltage gain as a function of particle velocity for the two cavities. The two cavity types can accelerate with $85 \%$ or more of peak efficiency over a velocity range from 15 to $53 \%$ the velocity of light. This covers an energy range from 10 to $170 \mathrm{MeV} /$ nucleon.

\subsection{Beam Steering}

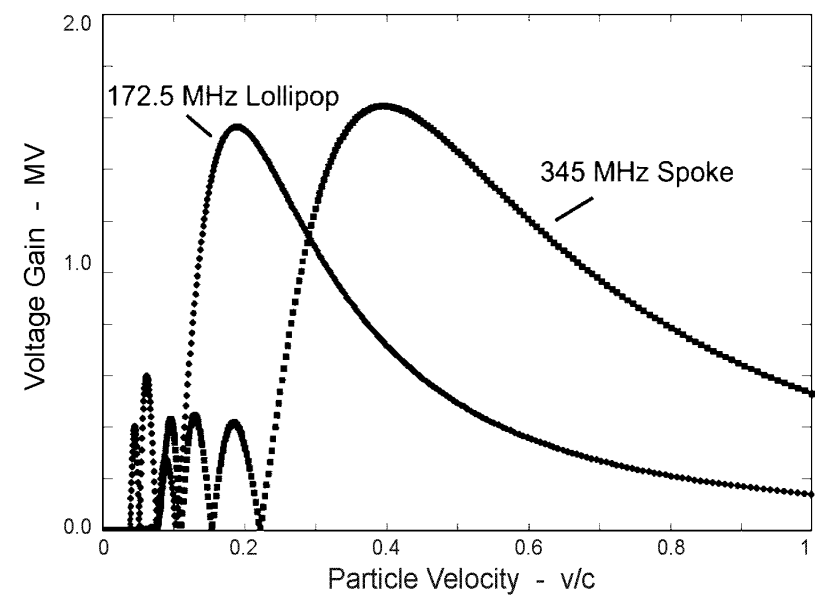

Figure 2: Voltage gain per unit charge as a function of particle velocity for the two cavities, each operating at a gradient of $5 \mathrm{MV} / \mathrm{m}$ and a phase of -30 .

The lollipop cavity can under some circumstances cause objectionably large beam steering. This problem surfaced when we increased the diameter of the inductive post to minimize the magnetic field. The post, however, introduces a substantial transverse electric field, particularly in the central accelerating gap. The horizontal component of the transverse field is shown in Figure 3 in the curve labeled 'no correction'.

The transverse electric field causes the beam to be steered an amount dependent on particle velocity and operating phase, as is shown in Figure 4 the curve labeled uncorrected.

Such transverse steering is particularly objectionable in the RIA driver linac, which must accelerate multiple 


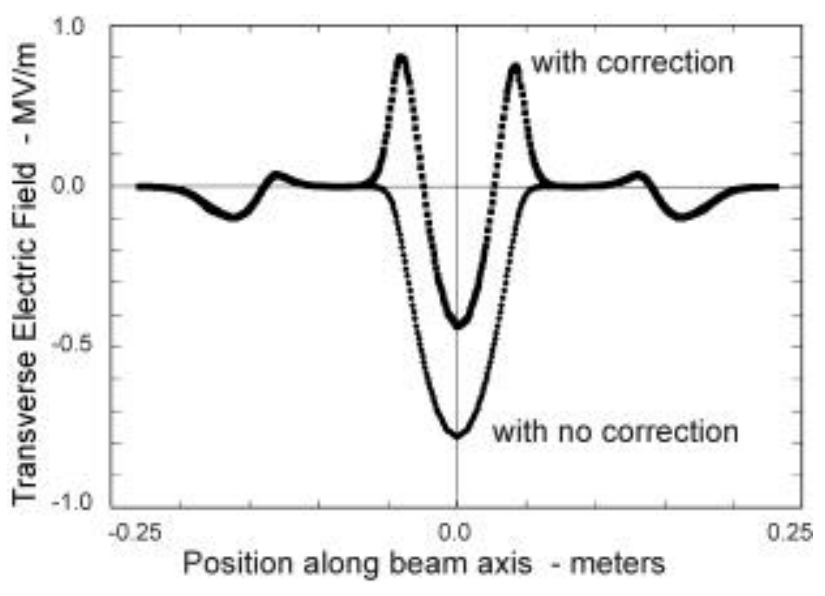

Figure 3: Transverse horizontal electric field along the beam axis of the $172.5 \mathrm{MHz}$ lollipop-loaded accelerating structure, shown for two different drift-tube designs.

charge state beams [8,9]: for multi-Q beams, steering, particularly at the lower velocities, can cause unacceptable emittance growth.

The steering can be greatly reduced by tilting the interior faces of each of the two drift-tubes by a rotation of 4 degrees about a horizontal axis perpendicular to the beam axis. As shown in Figure 3, this does not actually eliminate the transverse field, but rather introduces a counter-steering, so that the integrated effect, as shown in Figure 4 in the curve marked 'corrected', is to greatly reduce steering over the entire useful velocity range, from 0.15 c upwards.

\section{CONCLUSIONS AND FUTURE PLANS}

We have completed designs for two superconducting niobium cavities suitable for use in the RIA multi-beam driver linac for the velocity range from 0.15 to $0.55 \mathrm{c}$. The

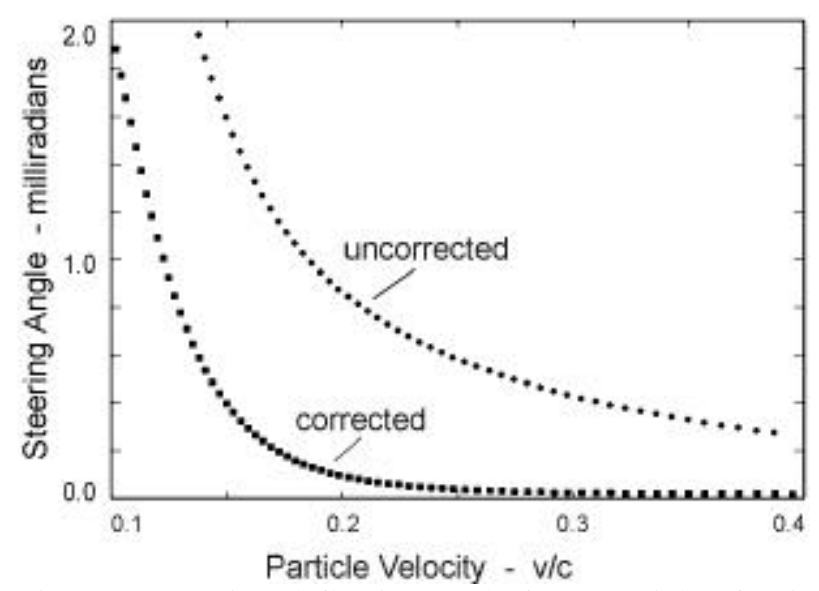

Figure 4: Steering deflection angle for a particle of unit charge to mass ratio accelerated through a single 172.5 $\mathrm{MHz}$ lollipop-loaded cavity operating at $5 \mathrm{MV} / \mathrm{m}$ and a phase of -30 . designs for both cavities exhibit good electromagnetic and mechanical properties, and are consistent with extrapolating from single-cell cavity performance to operation at gradients of $5 \mathrm{MV} / \mathrm{m}$ or higher [6,7].

Work is proceeding to complete and test prototype cavities. Tooling is currently under construction for forming elements of the two cavities from $1 / 8$ inch sheet niobium. Development of a niobium - vanadium stainless-steel weld transition which will enable electronbeam (EB) welding of the cavity into the housing is well advanced. Both cavity prototypes are expected to be complete in early 2002.

\section{ACKNOWLEDGEMENTS}

The authors would like to thank J. Rathke and E. Peterson of Advanced Energy Systems for useful discussions and suggestions concerning niobium forming and tooling design. We also acknowledge the contrib.ution of J. Brawley of JLAB in suggesting the use of vanadium to make an $\mathrm{EB}$ weld transition from niobium to stainless steel.

\section{REFERENCES}

[1] J. Nolen, et al., "An Advanced ISOL Facility Based on ATLAS", in the proceedings of the Eighth International Conference on Heavy-ion Accelerator Technology, October 5-9, 1998, Argonne, Illinois , 477 (1999).

[2] Guy Savard, "The U. S. RIA Project", in the proceedings of this conference.

[3] K. W. Shepard, et al., "SC Driver Linac for a Rare Isotope Facility“, in the Proceedings of the $9^{\text {th }}$ Workshop on RF Superconductivity, November 1-5, 1999, Santa Fe, N.M., 345 (2000).

[4] K. W. Shepard and T. Tretyakova, "Superconducting Accelerating Structures for a Multi-beam Driver Linac for RIA", in Proc. of the XX International Linear Accelerator Conference, Monterey, California, August 21-25, 2000, 920 (2001).

[5] J. Delayen et al., "Design Considerations for Highcurrent Superconducting Ion Linacs", in Proc. 1993 Particle Accelerator Conf., May 17-20, 1993, Washington, D. C., 1715 (1993).

[6] M. P. Kelly, K. W. Shepard, and M. Kedzie, "Cold Tests of a Spoke Cavity Prototype for RIA", in the proceedings of this conference.

[7] Frank Krawczyk, et al., "Evaluation and Testing of a Low-â Spoke Resonator", in the proceedings of this conference

[8] P. N. Ostroumov, J. A. Nolen, and K. W. Shepard, "Multiple-charge Beam Dynamics in an Ion Linac", in Proc. of the XX International Linear Accelerator Conference, Monterey, California, August 21-25, 2000,1018(2001). 